\title{
OS FATORES CONDICIONANTES PARA O EMPREENDEDORISMO FEMININO LOCAL:
} UM OLHAR PARA OS EMPREENDIMENTOS EM SÃO JOSÉ DO BELMONTE-PE

THE CONDITIONING FACTORS FOR LOCAL FEMALE ENTREPRENEURSHIP: A LOOK AT THE DEVELOPMENTS IN SÃO JOSÉ DO BELMONTE-PE

Recebido em 12.03.2021 Aprovado em 17.05.2021

\section{Rayla da Silva Santos}

rayllasanttos42@gmail.com

Universidade Federal Rural de Pernambuco - Serra Talhada/PE, Brasil

0000-0002-3135-2047

\section{Renan Silva Ferreira}

renansilvaferreirax@gmail.com

Universidade Estadual do Oeste do Paraná/PR, Brasil

0000-0002-6182-4121

\section{Resumo}

O objetivo deste artigo consiste em explorar os perfis e fatores condicionantes que impulsionam o empreendedorismo feminino na cidade de São José do Belmonte-PE. Para tal, a metodologia adotada classifica a pesquisa como qualitativa de cunho exploratória e descritiva. Por fim, os resultados foram obtidos com êxito, pois delimitamos as características sociodemográficas que descrevem o grupo de empreendedoras locais, bem como assimilamos os propósitos e aspirações que conduziram a escolha dessa atividade laboral.

Palavras-chave: Empreendedorismo. Empreendedorismo feminino. Empreendedoras locais.

\begin{abstract}
The purpose of this article is to explore the profiles and conditioning factors that drive female entrepreneurship in the city of São José do Belmonte-PE. To this end, the methodology adopted classifies the research as qualitative of an exploratory and descriptive nature. Finally, the results were obtained successfully, as we delimit the sociodemographic characteristics that describe the group of local entrepreneurs, as well as assimilate the purposes and aspirations that led to the choice of this work activity.
\end{abstract}

Keywords: Entrepreneurship. Female entrepreneurship. local entrepreneurs. 


\section{Introdução}

A representatividade feminina no campo econômico aumenta formidavelmente com o passar dos anos, evolução de uma luta histórica que permeia por séculos na humanidade combatendo muitas adversidades para o alcance do básico, igualdade de gênero e liberdade. No presente, as estatísticas demonstram que a maior fatia da população brasileira é composta por mulheres, cerca de 51,8\%, em relação aos homens que representam 48,2\%, conforme o IBGE (2019), entretanto, sintetizando essa questão deduzimos que apesar do progresso, o público feminino encontra-se ainda em menores proporções no mercado de trabalho, principalmente quando se trata de cargos de liderança, descartando a ideia de que a mulher está em um patamar análogo ao homem no universo corporativo.

Uma pesquisa da International Business Report (IBR) - Women in Business (2019), realizada pela Grant Thornton, afirma que o percentual de mulheres atuantes em cargos de liderança é de 25\% no Brasil e $29 \%$ de forma global. Mediante essa perspectiva, assumir o próprio negócio resulta em um fenômeno protagonizado por mulheres que por oportunidade ou necessidade buscam apoderar-se de um lugar no mercado. Nessa conjuntura, o exercício de empreender, como livre iniciativa, gera uma onda propícia ao empoderamento e ascensão à liderança feminina.

À vista disso, o objetivo do artigo é explorar os perfis e os fatores condicionantes que impulsionam o empreendedorismo feminino no município de São José do Belmonte-PE. De forma específica, o intuito é traçar e caracterizar os perfis das empreendedoras, descrever e interpretar os principais fatores que levam o empreendedorismo local e investigar e refletir sobre os obstáculos e as motivações encontradas ao comandar um empreendimento.

A dimensão do engajamento feminino no empreendedorismo traduz impactos que vão além da economia, tornando-se caminhos para mudanças mais justas na esfera social e no auxílio da destruição do mito patriarcal de inferioridade, que promovia a exclusão feminina em vários setores e limitava seu papel na sociedade. Ressalvamos, a partir das reflexões, a relevância referente às questões de gênero, relacionada diretamente ao ambiente produtivo, pois apesar das diversas alterações, as mulheres ainda lutam a cada dia para superar esse enigma e obter sua devida valorização (COSSO, 2014), e enquanto não atingirmos um sistema de igualdade, cabe a nós levantar a voz e buscar espaço (NOVAES, 2012).

Então, para uma melhor compreensão do artigo em questão, os elementos textuais foram estruturados em cinco partes específicas, são essas: a introdutória, que é a primeira. Sucedendo assim para a segunda, composta pela fundamentação teórica, em que apresentamos os principais entendimentos a respeito da temática. No terceiro ponto demostramos os aspectos metodológicos que conduziram a pesquisa. Em quarto lugar apresentamos a análise e discussão dos resultados e na quinta e última parte apresentamos as considerações finais.

\section{Fundamentação teórica}

\section{Contextualização histórica e conceitual sobre o empreendedorismo}

Desde o início, o ser humano sempre atuou como um agente inovador, dado pela busca incessante de soluções práticas para garantia da sua sobrevivência ou comodidade, seja pela criação ou aperfeiçoamento de algo existente. Logo, o empreendedorismo pode ser, por muitos, considerado como um campo de estudo atual, não obstante, é explícito pelo contexto histórico que as práticas empreendedoras já permeiam por séculos na humanidade, as quais conquistaram maior destaque após serem vistas como possibilidade de fomento para o desenvolvimento econômico. 
Em conformidade com isso Landstrom, Harirchi e Astrom (2012) afirmam que o empreendedorismo é uma função tão antiga quanto o intercâmbio e o comércio entre indivíduos, mas, que veio ganhar maior visibilidade após o surgimento dos mercados econômicos, durante a idade média, despertando em diversos autores o interesse pela área. O termo ganhou inúmeras contribuições e gerou várias interpretações pelos estudiosos, isso implica que não há uma concordância exata sobre um conceito, logo, para um posicionamento assertivo e crítico é preciso uma retomada histórica para analisar o pensamento dos principais autores.

Os primeiros indícios a respeito do empreendedorismo foram introduzidos por Richard Cantillon (1755) no seu livro Essai sur la Nature du Commerce en Général, que identificava o empreendedor como alguém que corre riscos inerentes, devido à impossibilidade de previsão no mercado e que assume a incerteza sobre a venda de sua mercadoria e geração de lucro. Para Cantillon (1755) esse termo se traduz pelo entusiasmo de enfrentar os desafios e variáveis presentes no negócio, sempre com uma tomada de decisão cautelosa baseada na razão a fim de criar valor.

Posteriormente, outro pioneiro a contribuir para o estudo do empreendedorismo foi Adam Smith (1776) em A riqueza das nações, conforme Carvalho e Costa (2015):

[...] na sua obra ele distingue três tipos de empresários: 1) o aventureiro ou especulador que investe o seu capital em empreendimentos de elevado risco; 2) o projetor que arquiteta e realiza planos, produz invenções de forma arriscada; 3) o empreendedor que realiza projetos medindo riscos e agindo de forma mais ponderada. Nesta obra, Adam Smith define os empreendedores como pessoas que reagem às mudanças económicas e têm a capacidade, enquanto agentes económicos, de transformarem a procura em oferta (CARVALHO; COSTA, 2015, p. 15).

Reforçando a ideia do empreendedor como um empresário atento às oportunidades, administrador e propício para a criação de riqueza.

Respeitando a ordem cronológica, salientamos o autor de Jean Baptiste Say que "contribuiu para o pensamento econômico ao enfatizar o empreendedorismo como o quarto fator de produção, junto com os fatores mais tradicionais: terra, trabalho e capital" (BRUE, 2006, p. 130). Isto é, amplificando o entendimento e ratificando a importância do empreendedorismo que passou a ser visto como elemento essencial para a produção de serviços ou bens úteis e rentáveis.

Há ainda a teoria econômica Schumpeteriana, que enriqueceu o empreendedorismo ao associá-lo com o processo de inovação. Schumpeter (1985, apud BRAGA, 2010), entende que empreender é inovar a ponto de gerar viabilidade para uma radical transformação de um determinado setor, ramo, território, em que o empreendedor atua: novo ciclo de crescimento, capaz de gerar uma ruptura no fluxo econômico contínuo, como descrito pela teoria econômica neoclássica.

A dinâmica de interesses pelo empreendedorismo foi traduzida em inúmeras contribuições para sua evolução e contextualização, frente à ideia da era econômica os referidos autores foram os principais protagonistas que influíram na teoria a respeito do empreendedor, com concepções e opiniões que são pontos de partida para o entendimento desse amplo campo de estudo.

Perante a esse contexto, podemos compreender que o termo empreendedorismo "é um neologismo derivado da livre tradução da palavra entrepreneurship e utilizado para designar os estudos relativos ao empreendedor, seu perfil, suas origens, seu sistema de atividades, seu universo de atuação" (DOLABELA, 1999, p. 43).

Para Schumpeter (1988) o termo empreendedorismo era definido como um processo da chamada destruição criativa, teoria desenvolvida que sinaliza a essência do capitalismo, em que se torna possível a eliminação daquilo existente para a criação do novo a fim de gerar crescimento econômico.

O agente condutor dessas mudanças, o empreendedor, segundo McClelland (1961, p.79), "é alguém que exerce certo controle sobre os meios de distribuição e produz mais do que pode consumir, com o objetivo de vendê-lo (ou trocá-lo) para obter uma renda individual (ou doméstica)". De acordo com Leite (1988, p.117), o empreendedor "é aquele que faz as coisas acontecerem, pois, além de ser capaz de identificar oportunidades de 
mercado, possui uma aguçada sensibilidade financeira e de negócios, para transformar aquela ideia em um fato econômico em seu benefício" Já para Filion (1999, p. 19), em vistas a um pensamento mais moderno, "um empreendedor é uma pessoa que imagina, desenvolve e realiza visões".

Assim, empreender não se limita apenas a apropriar-se ao risco, desafiar as incertezas, quebrar os paradigmas e conduzir ações que tenham como parâmetro a inovação e a criatividade. As atuais expectativas sobre o empreendedorismo devem ter amplitudes que extrapole o olhar capitalista, sendo necessário enxergar outros aspectos que possibilite o seu incremento no desenvolvimento social e cultural.

Como afirmam Hisrich e Peter (2004) "o papel do empreendedorismo no desenvolvimento econômico envolve mais do que apenas o aumento de produção e renda per capita; envolve iniciar e constituir mudanças na estrutura do negócio e da sociedade" (HISRICH; PETER 2004, p. 33).

Logo, sintetizando esse ponto, diríamos que o empreendedorismo pode ser visto como a competência que pessoas têm de identificar os problemas e oportunidades, elaborar soluções e dedicar recursos na criação de algo que seja positivo para a coletividade, seja um negócio, um projeto ou até mesmo movimentos que promova modificações significativas e afetem beneficamente o cotidiano das pessoas (SEBRAE, 2019). Nessa reflexão emblemática notamos que a missão do empreendedorismo deixa de ser apenas geração de recursos e passa a ser vista como uma solução para as diversas questões políticas e de proveito para a criação de um cenário mais justo e harmônico.

\section{Breve trajetória feminina no mercado de trabalho}

Analisando historicamente, podemos entender que por um longo período, mais precisamente antes da Revolução Industrial e da formação da sociedade moderna/pós-moderna (século XVIII e século XIX) os valores morais e sociais eram determinados pelo patriarcado que utilizava de privilégios e poder para controlar e limitar as atividades femininas. Usufruindo assim de alegações preconceituosas que excluía a influência das mulheres nas diversas instâncias sociais (DANDOLINI, 2018).

Amorim e Batista (2012) demonstram que um dos grandes impulsionadores da introdução da mulher no mercado de trabalho surgiu no século XX, diante da $1^{a}\left(1914\right.$ - 1918) e $2^{a}$ Guerra Mundial (1939 - 1945), em que a ausência masculina pela necessidade de combater esses confrontos ocasionou na contratação de mulheres para cargos que pertencia exclusivamente a homens. "Nesse período nascem os primeiros movimentos feministas", que foram espaços onde "as mulheres começaram uma luta mais organizada por seus direitos e pela igualdade de oportunidades no trabalho" (AMORIM; BATISTA, 2012, p. 03).

No cenário brasileiro, um marco histórico que devemos mencionar sobre a conquista dos direitos femininos diz respeito à promulgação da Constituição da República Federativa do Brasil de 1988, que alega a igualdade de homens e mulheres nos direitos e obrigações. Para Lopes (2006), esse avanço implica na:

[...] superação de um paradigma jurídico que legitimava declaradamente a organização patriarcal e a consequente preferência do homem ante a mulher, especialmente no locus da família. Em seu lugar, delineia-se uma ideologia de igualdade de direitos e deveres. Desaparece a figura da chefia da sociedade conjugal e com ela as preferências e privilégios que sustentavam juridicamente a dominação masculina (LOPES, 2006, p. 407).

Logo, essa modificação radical que promoveu um progresso jurídico nos direitos femininos se alastra até os dias atuais, e pode ser entendida como pontapé inicial para o fortalecimento da mulher em todos os âmbitos.

Fazendo uma breve recapitulação da inserção da mulher no mercado, após o enfrentamento de muitos obstáculos herdados pela cultura de domínio e repressão e pela multiplicidade de tarefas associadas ao papel feminino, Raposo e Astoni (2007) acentuam que:

“Em 1940, quase metade, (48\%) da população ativa feminina era focada no setor primário da economia, basicamente na agricultura. Em 1990, mais de dois terços (74\%) da população economicamente ativa feminina era concentrada no setor terciário, ou seja, em serviços, principalmente em alguns setores da economia, como atividades comunitárias, áreas voltadas à 
educação, serviços de saúde e principalmente serviços domésticos. Hoje, versatilidade é a qualidade que resume a condição atual da vida feminina" (RAPOSO; ASTONI, 2007, p. 3637).

Diante o exposto, podemos afirmar que no presente a mulher contemporânea tem mais liberdade para escolher seu destino e inclusive criá-lo, como por exemplo, retratamos a expansão de empreendimentos fundados e administrados por mulheres, embora haja ainda alguns empecilhos fruto dessa trajetória passada que precisam ser erradicados.

\section{Empreendedorismo feminino: abordagens conceituais, motivações e dificuldades}

Campos e Teixeira (2014) afirmam que as primeiras definições sobre o empreendedorismo contemplavam quase exclusivamente os homens, já que não era comum a participação feminina nesse âmbito. Isso justifica o fato de que em torno de toda essa contextualização e conceituação sobre o empreendedorismo nada foi citado em relação à diferença de gêneros.

Um dos primeiros estudos intrínseco ao empreendedorismo feminino surgiu da década de 1970, pela autora Schwartz (1976) no seu artigo: Entrepreneurship: a new female frontier. Conforme Schwartz (1976, apud Miranda, 2007) a publicação traçou aspectos que identifica nas mulheres características de personalidade, motivações e desafios. Além de reafirmar a ideia de que as qualidades empreendedoras podem ser desenvolvidas por ambos os gêneros, sem haver quase nenhuma dessemelhança nessas.

Apesar de citado na literatura estrangeira anteriormente, no Brasil o discurso do empreendedorismo feminino veio a ser estudado no fim dos anos 1990, movido pelas propostas que buscam análises mais acuradas para compreender o que estimula as mulheres nos negócios (SOUZA, 2020).

Para Gomes et al. (2014) “um dos artigos que inaugurou a produção acadêmica brasileira, com projeção nacional, foi o de Machado (1999), apresentando as tendências do comportamento gerencial da mulher empreendedora baseadas na compilação de estudos anteriores". Ainda pela óptica do autor, "especificamente, no Brasil, verificou-se que a maior parte dos estudos é realizada por pesquisadoras vinculadas a instituições das regiões Sul e Sudeste do Brasil”' (GOMES et al., 2014, p. 328).

Desde então, as pesquisas sobre o empreendedorismo feminino não estagnaram, pelo contrário, elas estimularam a pesquisa e publicação de vários periódicos sobre o assunto, que começaram a explorar diversas dimensões atribuídas a esse, como por exemplo, o comportamento das empreendedoras, competências, gestões, riscos inerentes à concessão de crédito, descriminações, obstáculos, motivações e outras.

Simplificando essa ideia, diríamos que as empreendedoras são fenômenos culturais que surgem pelo meio que vivem, ou por conta de alguma circunstância, isto é, são inúmeros os fatores que influenciam para a criação de empresas por mulheres (DOLABELA, 1999). Mas temos uma certeza, sejam elas "motivadas por vislumbrarem alguma oportunidade ou impulsionadas pelas necessidades, as mulheres empreendedoras escrevem atualmente um novo capítulo na história do empreendedorismo mundial" (CAMPOS; TEIXEIRA, 2014, p. 60).

Isso retrata que há inúmeros fatores determinantes que influenciam o empreendedorismo feminino, ainda por Schwartz (1976, apud Miranda, 2007) podemos notar que empreender está associado ao desejo de realização, de obtenção de uma renda, o que proporciona autoestima nas mulheres e faz com que isso se torne parte de suas características.

Gomes e Santana (2009) afirmam no seu estudo que um dos aspectos primordiais que leva as mulheres a optarem por empreender é sem dúvidas a obtenção de flexibilidade na carga horária, isso associado a uma organização proporciona maiores chances de conciliação da vida profissional com a família.

Além dessas, deve-se considerar também a liderança, fator que está atrelado intimamente ao empreendedorismo e que proporciona as mulheres voz e visibilidade, contribuindo ainda para estimular as mulheres a montarem seu negócio e fazerem parte de um movimento que só cresce, afinal, a inserção feminina no mercado de trabalho caminha para um uma maior igualdade social (SEBRAE, 2020).

ISSN 2318-9231

CGE | Rio de Janeiro | v. 9 | n. 1 | jan. - abr. 20215 
Contudo, independentemente das questões que levem a mulher a assumir o papel de empreendedoras, isso vem viabilizando a desnaturalização de suposições preconceituosas acerca da capacidade feminina, gerando emprego e renda principalmente para as mulheres e acarretando em uma maior adesão a liderança, independência e autonomia. Além disso, o empreendedorismo proporciona que elas sejam protagonistas de suas próprias vidas, livrando-as de situações de submissão, subordinação e até mesmo violência.

\section{Procedimentos metodológicos}

A pesquisa foi aplicada no município de São José do Belmonte-PE, localizado na Mesorregião do Sertão Pernambucano e na microrregião Salgueiro, onde possui uma população estimada em 34.021 habitantes, conforme estimativas do IBGE (2020). Como o foco do artigo é estudar a parcela da população composta pelas mulheres empreendedoras do município mencionado, é necessário adotar alguns aspectos metodológicos que validem esse estudo. Para tal empregou-se uma pesquisa de natureza qualitativa do tipo exploratória e descritiva, considerando a contribuição bibliográfica para o embasamento teórico minucioso.

Nessa conjuntura, compreendemos a pesquisa qualitativa como um mecanismo que envolve diversas técnicas para coleta e averiguação de dados, como, por exemplo, observações, entrevistas, discussões e outras que tenham por finalidade reunir e gerar o máximo de informações a serem analisadas para desvendar seus significados e incrementar tal estudo (APPOLINÁRIO, 2009).

Seguindo a linha de pensamento e em conformidade com objetivo proposto é patente que a pesquisa tenha ainda propriedades exploratória e descritiva. A primeira nomenclatura tem por intenção prover uma maior familiaridade com o problema apontado, com vistas a torná-lo mais explícito ou a constituir hipóteses, isto é, a fim de aprimorar as ideias ou a descoberta de intuições, segundo Gil (2002). Já "as pesquisas descritivas têm como objetivo primordial a descrição das características de determinada população ou fenômeno ou, então, o estabelecimento de relações entre variáveis" (GIL, 2002, p.42).

No presente, o levantamento de dados foi viabilizado mediante aplicação de um questionário semiestruturado composto por 19 questões, sendo 8 objetivas e 11 discursivas, desenvolvido de acordo com os objetivos do artigo e direcionado as empreendedoras de São José do Belmonte de diversos segmentos, sendo encaminhado inicialmente a uma amostra de 40 mulheres que se incluísse no perfil, em que contabilizamos um retorno total de 30 respostas até o prazo determinado.

A coleta foi realizada durante os dias 23 a 30 de janeiro de 2021, por acesso remoto via internet, medida adotada como forma de segurança em decorrência ao enfrentamento da pandemia do Coronavírus (COVID-19) - uma doença infecciosa que surgiu inicialmente em Wuhan, na China, em dezembro de 2019, sendo disseminada por diversos países e declarada pela OMS como pandemia. Como instrumentos para obtenção das informações, empregou-se três plataformas gratuitas e de fácil acesso pelo público: Google Forms, Whatsapp e Instagram. O questionário on-line foi conveniente para o desenvolvimento da pesquisa, pois além de reunir informações dispõe de gráficos e planilhas para uma melhor análise dos resultados. Já Whatsapp e Instagram foram aplicados para abordar o alvo do estudo. Mediante esses processos, foi possível detectar as descrições gerais das empreendedoras, compatível para a determinação de um perfil, bem como os fatores condicionantes para o aparecimento e crescimento do empreendedorismo feminino.

\section{Apresentação e análise dos resultados}

\section{Análise descritiva}

Extraindo os dados do questionário, certifica-se que das 30 empreendedoras de São José do Belmonte que contribuíram para a pesquisa, $25(83 \%)$ afirmam que essa é sua principal atividade como fonte de renda, em relação a $5(17 \%)$ que classificaram seu empreendimento como atividade extra. Isso significa que a maioria das 
mulheres depende exclusivamente do seu empreendimento para fornecer seu sustento e garantir ainda o de seus dependentes, caso tenha. A sintetização desses dados é apresentada no Gráfico 1, na sequência:

Gráfico 1 - Indicação do empreendedorismo como atividade principal para fonte de renda e atividade extra.

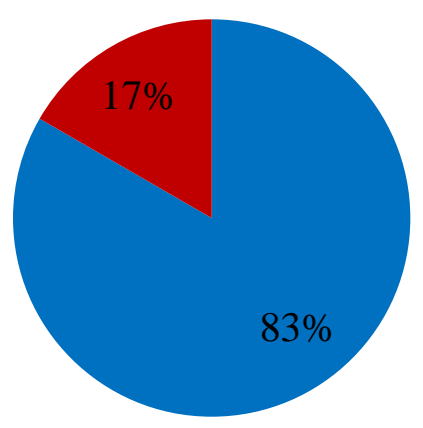

- Atividade Principal

- Atividade Extra

Fonte: Dados da pesquisa, 2021.

A faixa etária da amostra das mulheres teve uma leve oscilação, sendo possível identificar, de modo geral, que as mulheres são bem jovens. Entre essas 1 (3\%) tem menos de 18 anos, 12 (40\%) dessas têm de 18 a 25 anos completos, 14 (47\%) estão na faixa de 25 a 35 anos completos, 2 (7\%) possuem de 35 a 45 aos completos e apenas $1(3 \%)$ afirma ter mais de 45 anos. Como demonstra o Gráfico 2:

Gráfico 2 - Faixa etária das respondentes

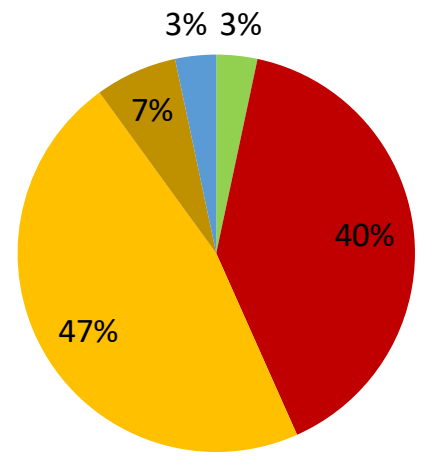

\author{
Até 18 anos incompletos \\ 18 anos completos a 25 \\ anos incompletos \\ 25 anos completos a 35 \\ anos incompletos \\ 35 anos completos a 45 \\ anos incompletos
}

Fonte: Dados da pesquisa, 2021.

A respeito do nível de escolaridade, do total das correspondentes, 15 (50\%) afirmam ter ensino médio completo ou incompleto, $12(40 \%)$ cursam ou cursaram ensino superior e $3(10 \%)$ estão em fase de pósgraduação, sendo perceptível um resultado positivo em relação a esse aspecto. Inclusive, ao compararmos com os dados do último relatório da Global Entrepreneurship Monitor (GEM) 2019, notamos que a média do nível escolar da população feminina no Brasil é um ponto superior a média do homem, isso deixa claro que não é a educação que interfere nos índices de desigualdade na atividade empreendedora. Podemos observar pelo Gráfico 3 :

Gráfico 3 - Nível de escolaridade das respondentes 


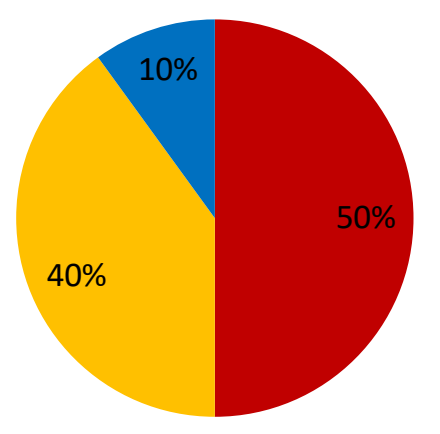

Ensino fundamental completo ou incompleto

Ensino médio completo ou incompleto

Ensino superior completo ou incompleto

- Pós-graduação

Fonte: Dados da pesquisa, 2021.

Em relação a renda mensal das mulheres, 11 (36\%) declararam ganhar até um salário mínimo, 12 (40\%) alegaram faturar de 2 a 3 salários mínimos, 5 (17\%) alcançam na marca de 3 a 4 salários mínimos e 2 (7\%) tem uma renda superior a 4 salários mínimos. Como podemos visualizar no Gráfico 4:

Gráfico 4 - Renda mensal das respondentes

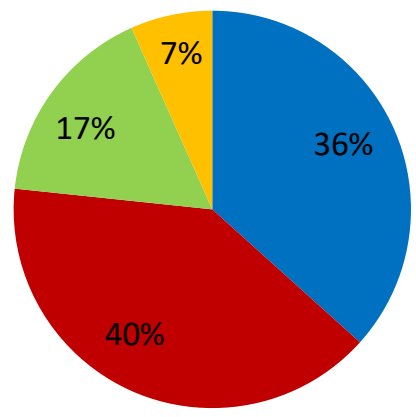

- Até 1 salário mínimo

- 2 a 3 salários mínimos

๑ 3 a 4 salários mínimos

Mais de 4 salários mínimos

Fonte: Dados da pesquisa, 2021.

Dessas, apenas $1(3 \%)$ demonstra insatisfação com sua renda mensal, $6(20 \%)$ se sentem pouco satisfeitas, 16 (54\%) demonstram satisfação em relação a seu ganho mensal e 7 (23\%) afirmam estar muito satisfeitas. Isso significa que o empreendimento está suprindo suas expectativas em relação aos ganhos, o que varia também de acordo com a perspectiva de crescimento de cada uma. Como podemos notar em seguida no Gráfico 5:

Gráfico 5 - Satisfação e relação à renda das respondentes

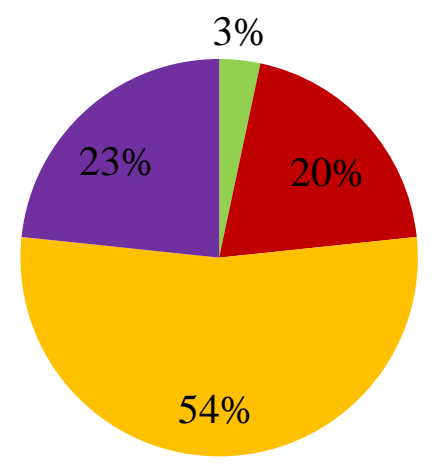

Insatisfeita

- Pouco satisfeita

Satisfeita

- Muito satisfeita

Fonte: Dados da pesquisa, 2021. 
A respeito do estado civil das respondentes, $17(56 \%)$ responderam que são solteiras, $8(27 \%)$ casadas e 5 (17\%) divorciadas, em que 14 (46,7\%) dessas são mães, conforme apresentamos no Gráfico 6:

Gráfico 6 - Estado civil das respondentes

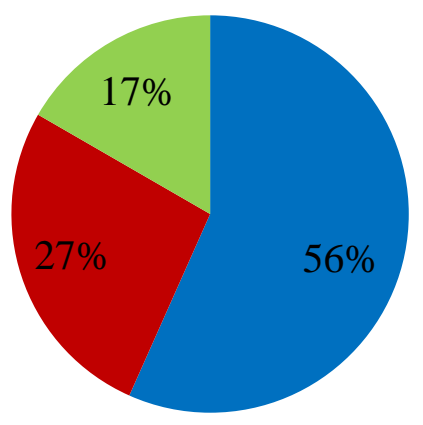

- Solteira

- Casada

Divorciada

Viúva

Fonte: Dados da pesquisa, 2021.

Concluímos que o perfil das empreendedoras de São José do Belmonte é de mulheres jovens, com idades entre 25 a 35 anos incompletos (46,7\%), que têm seu empreendimento como principal fonte de renda (83,3\%), de nível escolar médio completo (50\%), com renda mensal de 2 a 3 salários mínimos (40\%), solteiras (56,7\%) e sem filhos $(53,3 \%)$.

A respeito dos motivos que incentivam as mulheres a optarem por investir e abrir seu próprio negócio, compreendemos a busca pela independência financeira como condicionante primordial para o ingresso nessa atividade. Como podemos perceber pelos dados da Tabela 1:

Tabela 1 - Fatores condicionantes ao empreendedorismo feminino em São José do Belmonte.

\begin{tabular}{lcc}
\hline Fatores & Frequência & Porcentagem \\
\hline Continuidade de um negócio de família & 02 & $6,7 \%$ \\
Desemprego & 03 & $10 \%$ \\
Independência financeira & 15 & $50 \%$ \\
Interesse ou paixão pelo empreendedorismo & 09 & $30 \%$ \\
Liderança & 01 & $3,3 \%$ \\
Visão de oportunidade de mercado & 00 & $0 \%$ \\
\hline Total & 30 & $100 \%$ \\
\hline
\end{tabular}

Fonte: elaboração própria (2021)

Além disso, identificamos que os principais nichos de mercados apostados pelas empreendedoras foram os de serviço e comércio, em que notamos uma maior atuação em estéticas e nos salões de beleza, como ilustra a Tabela 2:

Tabela 2 - Segmentação de mercado

\begin{tabular}{lll}
\hline Segmentos & Frequência & Porcentagem \\
\hline Alimentação & 03 & $10 \%$ \\
Confeitaria & 03 & $10 \%$ \\
Decoração & 01 & $3,3 \%$ \\
Educação & 01 & $3,3 \%$ \\
Estética & 05 & $16,6 \%$ \\
Maquiagem & 03 & $10 \%$ \\
Varejo de bijuterias & 01 & $3,3 \%$ \\
Varejo de calçados e acessórios & 01 & $3,3 \%$ \\
Varejo de cosméticos & 01 & $3,3 \%$ \\
Varejo e atacado de joias & 01 & $3,3 \%$ \\
Vestuário feminino & 04 & $13,3 \%$ \\
\hline
\end{tabular}

ISSN 2318-9231

CGE | Rio de Janeiro | v. 9 | n. 1 | jan. - abr. 20219 


\begin{tabular}{lll}
\hline Vestuário feminino, masculino e infantil & 01 & $3,3 \%$ \\
Salão de beleza & 05 & $16,6 \%$ \\
\hline Total & 30 & $100 \%$ \\
\hline
\end{tabular}

Fonte: elaboração própria (2021)

Portanto, ao explorar as variáveis sociodemográficas e os fatores determinantes para a inserção feminina no exercício empreendedor, conseguimos resultar em um perfil detalhado e na razão inicial que leva a mulher a empreender. Mais adiante levantaremos demais interpretações resultadas das questões discursivas e do engajamento das mulheres com a pesquisa.

\section{Análise descritiva}

As prerrogativas presentes nas questões abertas além de levantar reflexões aproximam a realidade das empreendedoras consolidando uma relação da prática com a teoria por meio dos seus discursos.

Ao indagar sobre os fatores iniciais que conduziram ao empreendedorismo, foi deixado um espaço a critério para justificativa e complemento da escolha pelas respondentes, o que gerou vertentes importantes fora as que estavam em pauta, como: a autoestima e flexibilidade de horários.

Diante esse parecer, evidenciamos que o desejo de contribuir com as despesas de casa, fornecer o sustento dos seus filhos e não depender de terceiros proporciona uma realização que vai além do financeiro. Ideia que permeia desde o surgimento do empreendedorismo feminino. Pelo ponto de vista de Schwartz (1976, apud Miranda, 2007) a autora relaciona a necessidade de trabalhar com a satisfação, e indica a autoestima como atributo a essas mulheres. De acordo ainda com dados de uma pesquisa realizada por Jonathan (2011) identificamos que a experiência de empreender proporciona uma vivência relacionada ao bem-estar, com fortes sentimentos a respeito da satisfação pessoal e de autorrealização, em que a liberdade, criatividade e reconhecimento do seu trabalho e das suas conquistam favorecem a promoção de autoestima.

A respeito da flexibilidade dos horários, Boden Jr. (1999 apud JONATHAN, 2011) menciona que, de modo complementar e diferente do que acontece com os homens, a flexibilidade de horário bem como motivos familiares são apontadas como razões que impulsionam as mulheres no desejo de serem donas do seu próprio negócio. Ao empreender as mulheres adquirem a liberdade de gerenciar seu horário de trabalho, mas devemos lembrar ainda que isso não significa que há menos trabalho ou menos responsabilidade, realça apenas a ideia de que é possível uma melhor organização e consequentemente otimização do tempo.

Ressaltamos tais questões com alguns depoimentos selecionados das participantes a seguir:

Participante 02: "[...] a independência financeira ajuda muito na autoestima, além de poder contribuir financeiramente em casa” (25 anos completos a 35 anos incompletos, segmento estética, casada e com filho).

Participante 07: "[...] busca pela independência financeira e também paixão pelo empreendedorismo, sempre fui uma pessoa criativa e inovadora, e foi na confeitaria onde consegui expandir meu talento. O que me motiva e me traz autoestima por poder conquistar minhas coisas" (18 anos completos a 25 anos incompletos, segmento confeitaria, solteira e sem filhos).

Participante 10: "[...] sempre fui independente. Desde muito nova, sempre tive "o gênio forte", como diria mainha! isso me levou a não querer depender unicamente e exclusivamente dos meus pais. Vi no empreendedorismo minha independência e minha paixão!" (18 anos completos a 25 anos incompletos, segmento vestuário, solteira e sem filhos).

Participante 15: "[...] no empreendedorismo tenho uma flexibilidade onde não necessariamente preciso me ausentar da educação do meu filho para trabalhar! Por isso, consigo lidar bem com essa dupla jornada! Amo ser mãe e empreender!" (18 anos completos a 25 anos incompletos, segmento varejo e atacado de joias, solteira e com filho).

Com o levantamento desse estudo, além de detectarmos os fatores que influíram para o empreendedorismo feminino, identificamos os principais desafios encontrados pelas mulheres para abrir um empreendimento, os quais são resumidos inicialmente na falta de capital. Conforme informações da pesquisa, muitas empreendedoras afirmam que realizaram atividades extras para conseguir dinheiro suficiente e assim investir em sua ideia, pois não queriam optar pela burocracia e endividamento oriundo do empréstimo, já outras assumiram esses riscos, apesar dos obstáculos apresentados e da dificuldade na concessão desse recurso. Então, concluímos que embora o empreendedorismo feminino represente alternativas profissionais de vasta relevância, "existe pouco acesso ao crédito em instituições financeiras e dificuldades no relacionamento entre mulheres empreendedoras e os fundos de capital de risco" (MACHADO, 2012, p.5).

Diante o exposto, podemos entender ainda que os impasses para conseguir investimentos expressivos tornam-se também desestímulos para abertura do negócio, o que faz muitas mulheres desistirem do empreendimento durante ainda o percurso inicial (SEBRAE, 2016). 
Enfatizamos essa ideia com as declarações a seguir:

Participante 04 : "[...] Comecei aos 15 anos, vendendo trufas na escola aos meus amigos, dai então fui juntando o dinheiro e aos meus 17 anos comecei a vende roupa feminina. No ano de 2019 surgiu o interesse em ter um ponto físico onde pudesse receber minhas clientes com mais conforto" (18 anos completos a 25 anos incompletos, segmento vestuário feminino, solteira e sem filho).

Participante 15: "[...] Tudo começou quando pedi dinheiro emprestado a meu pai (na época 300,00 reais) e comprei bolsas e óculos! Depois eu quebrei, mas não desisti e fiz minha primeira compra de joias no crediário (eu não tinha nem 1 real no bolso), "dei minha cara a tapa" e assim começou!" (18 anos completos a 25 anos incompletos, segmento varejo e atacado de joias, solteira e com filho).

Participante 28: "[...] Comecei quando estava na faculdade, aos 16 anos, vendendo salgados, depois de me formar veio o interesse de empreender no ramo varejista de calcados de uma forma mais organizada e planejada com a minha própria loja virtual e agora realizando um entre tantos sonhos colocando a loja física" (25 anos completos a 35 anos incompletos, segmento varejo de calçados e acessórios, solteira e com filho).

Compreendido os fatores condicionantes e a dificuldade, relatamos, por fim, para proporcionar uma reflexão alguns dos principais desafios enfrentados na contemporaneidade pela parcela feminina no exercício de empreender, que são: a discriminação de gênero, dúvidas relacionadas às competências no gerenciamento, machismo, assédio, opiniões de terceiros e sobrecarga de tarefas, como podemos perceber nas falas das empreendedoras:

Participante 01: "Os principais desafios inicialmente foi conciliar o trabalho com a criação das crianças além do cuidado na casa, porque antigamente isso era visto apenas como o papel da mulher, então muitas vezes tinha que enfrentar uma jornada de trabalho dupla e cansativa. Além disso, muitas críticas e opiniões negativas" (Mais de 45 anos completos, segmento salão de beleza, casada e com filhos).

Participante 10: "Resumidamente, ser mulher é dificil. Mas ser mulher empreendedora, é muito mais! Existe preconceito, machismo, achismo... um exemplo disso, é quando homens vão lá no perfil da sua loja, pegam seu telefone para contato e depois disso, vem ser inconveniente. Ou, como é o meu caso - que trabalho com peças intimas- muitas e muitas vezes, as meninas que participam dos ensaios, ficam constrangidas com a quantidade de compartilhamento em suas fotos! E não são apenas homens que fažer isso. São homens e mulheres! [...]"(18 anos completos a 25 anos incompletos, segmento vestuário, solteira e sem filhos).

Participante 13: "[...] Principalmente o machismo, dependendo tem deles que nem querem fechar negócio com uma mulher [...]" (25 anos completos a 35 anos incompletos, segmento salão de beleza, divorciada e com filhos).

Participante 15: "[...] Enfrentei MUITAS dificuldades e críticas! No inicio muitas pessoas (na maioria homens) não acreditavam em mim, e sempre tentavam me colocar pra baixo! Como também achavam que por eu ser autônomo (trabalho flexivel), eu não trabalhava! E sem contar a dificuldade que en tive por ter que conciliar o ser mãe com o trabalho, pois por 2 anos eu vendi porta a porta com meu filho no braco! E hoje, ainda existem críticas, principalmente por eu ser nova e mulher, mas consigo lidar bem com elas!" (18 anos completos a 25 anos incompletos, segmento varejo e atacado de joias, solteira e com filho).

Participante 17: "[...] são muitos desafios, e bem difícil, muitas pessoas não acreditam no nosso trabalho na nossa capacidade de conseguir alcançar os nossos objetivos [...]" (18 anos completos a 25 anos incompletos, segmento vestuário, solteira e sem filhos).

Participante 22: "[...] Sem dívidas o fato de acharem que mulher não pode colocar em prática suas ideias, as palavras negativas sobre dar errado por ter começado muito nova e ser mulher, foi um grande desafio." (18 anos completos a 25 anos incompletos, segmento alimentício, solteira e sem filhos).

Participante 25: "[...] Como mulher, conciliar a vida pessoal com o negócio, geralmente mães são as que mais passam por esses desafios. Desestimulo, menos incentivadas a se tornarem grandes empresárias" (18 anos completos a 25 anos incompletos, segmento varejo de bijuterias, solteira e sem filhos).

Com a obtenção dos resultados, notamos que apesar do forte desenvolvimento do papel da mulher na sociedade, graças às lutas femininas, há ainda muitos preconceitos que afetam negativamente e trazem prejuízos para a jornada das mulheres, dificultando seu crescimento profissional e sucesso. Com isso, compreendemos que a mulher quando decide empreender lida com uma barreira para enfrentar outra mais adiante, reafirmando a ideia de que ainda estamos distantes de uma igualdade substancial.

Então, o empreendedorismo é visto como uma grande oportunidade, pois permite a conquista da independência financeira, promove visibilidade e ainda poder para a libertação de situações de vulnerabilidade, o que justifica o seu crescimento constante na atualidade. Mas, devemos destacar os obstáculos atrelados a ele, que inclui dificuldades financeiras iniciais, preconceitos, discriminações e sobrecarga. Além disso, é dever evidenciar que a causa dessas dificuldades é oriunda de problemas estruturais, e para solucionar isso a mulher deve cada vez mais ocupar espaços, parar de naturalizar o inaceitável e não baixar a voz até que essa batalha seja vencida, até atingir 
um patamar de igualdade de gênero e até ter a total liberdade e responsabilidade por suas escolhas sem que sofra julgamentos.

Percebe-se assim, o impacto dos empreendimentos capitaneados por mulheres influencia no desenvolvimento de uma região tanto em âmbito econômico como no social, entre outras faces que o empreendedorismo pode afetar positivamente numa região, especialmente num mercado mais concentrado e de pequeno porte; as pequenas empresas, embora enfrentem diversos gargalos observados nas trajetórias identificadas nesta pesquisa, são enormes fontes de desenvolvimento, autoestima e auto realização feminina.

\section{Considerações finais}

A atual era econômica composta por diversas mudanças corriqueiras com efeitos da globalização possibilita, cada vez mais, o ingresso das pessoas em diversas atividades produtivas autônomas. Essa abertura vem proporcionando cada vez mais as mulheres empoderamento e representatividade no meio corporativo. Então, objetivo deste artigo foi identificar o perfil e explorar os aspectos condicionantes que influenciam as mulheres no ingresso do empreendedorismo, além de gerar uma discussão em torno dessa problemática.

Durante a realização da pesquisa, foram encontrados alguns obstáculos principalmente pela inviabilidade de realizar uma entrevista presencial em virtude da pandemia do Covid-19, pois o desejo era de conhecer mais de perto a realidade do objeto de estudo. Nesse aspecto foram considerados ainda alguns impasses no contato online com as empreendedoras, onde registramos a falta de disponibilidade, dificuldade de preenchimento pela ferramenta e incompatibilidade de horário, o que impediu a participação em tempo ágil de algumas mulheres. Além disso, pode-se considerar as dificuldades detectadas na pesquisa bibliográfica que reforça nossa fundamentação teórica, visto que muitas obras e artigos originais não estão disponíveis de forma gratuita.

Contudo, foi possível driblar essas questões e alcançar os objetivos propostos com maestria. Então, descrevemos as empreendedoras como mulheres na faixa etária de 25 a 35 anos, de nível escolar médio, em que atualmente possuem seu empreendimento como sua principal fonte de renda, ganhando assim de 2 a 3 salários, sendo elas solteiras e sem filhos, motivadas pela liberdade financeira e autonomia. A maioria dessas apostando e se especializando em segmentos específicos, onde realçamos os serviços de estéticas e salões de beleza.

O presente estudo contribui para realçar a voz dessas mulheres e oportunizar a promoção de seus trabalhos, além de enriquecer as teorias com seus relatos e experiências ao longo da construção de sua carreira. Graças à pesquisa, foi possível ainda conhecer e entender várias histórias de superação até o alcance do sucesso das empreendedoras do pequeno município do interior de São José do Belmonte-PE, que vêm recentemente conquistando demais regiões.

Nas questões analisadas ficou evidente que apesar do senso comum achar que a mulher está em um âmbito de igualdade, por atualmente ela ser livre para estudar, trabalhar e empreender, demonstrou-se que os dados colhidos provam o contrário, justificado por um passado de dominação masculina. Além disso, os resultados das pesquisas demonstram que apesar do progresso, a luta não estagna, ainda existe muito a percorrer, para que a mulher consiga escolher ser quem ela quiser sem desgastes ou sobrecargas.

A pesquisa foi limitada a seu objetivo proposto inicialmente, no entanto com a obtenção dos resultados, sugerimos que os novos estudos abordem novos aspectos condicionantes e variáveis ao olhar da mulher moderna e identifique demais carências e dificuldades, principalmente no que se referente à gestão dos empreendimentos para o desenvolvimento de alternativas que impacte positivamente nos negócios delas e auxiliem na obtenção de sucesso. Outras sugestões como estudos de caso mais precisos individualmente, ou a utilização de métodos mais minuciosos podem favorecer novas pesquisas e trazer olhares ainda mais analíticos à temática, a comparação entre variáveis e atividades empreendedoras entre homens e mulheres podem proporcionar um horizonte crítico; Além de em momentos oportunos e seguros possam ser desenvolvidas pesquisas presenciais. 


\section{Referências}

AMORIM, R. O. BATISTA, L. E. Empreendedorismo feminino: razão do empreendimento. Núcleo de Pesquisa da Finan, v. 3, n. 3, 2012. Disponível em:

http://uniesp.edu.br/sites/_biblioteca/revistas/20170602115149.pdf. Acesso em 10 jan. 2021.

APPOLINÁRIO, F. Metodologia da Ciência: filosofia e prática da pesquisa. São Paulo: Cengage Learning, 2009.

BRAGA, Ana. C. Weber e Schumpeter a ação econômica do empreendedor. Revista de Economia Política. v.30, p. 254-270, abril-junho, 2010.

BRUE, Stanley L. História do Pensamento Econômico. Trad. Luciana Penteado Miquelino. São Paulo: Thomson Learning, 2006.

CAMPOS, M.R; TEIXEIRA, R. M. Empreendedorismo feminino e o conflito trabalho-família: estudo de multicasos no setor de comércio de material de construção da cidade de Curitiba. Revista de Administração, São Paulo, 2014.

CANTILLON, Richard. Ensaio sobre a natureza do comércio em geral. Trad. Fani Goldfarb Figueira. Curitiba: Segesta Editira, 2002.

CARVALHO, L; COSTA, T. Empreendedorismo - Uma Visão Global e Integradora. Edições Sílabo. $1^{\text {a }}$ Edição - Lisboa, 2015.

COSSO, Esther. Perfil de Empreendedoras Femininas: estudo de caso do núcleo das mulheres empreendedoras da associação comercial e industrial de Santo André - SP. 2014. 107 f. Dissertação (Mestrado em Gestão de organizações) - Universidade Metodista de São Paulo, São Bernardo do Campo, 2014.

DANDOLINI, Adriana de Oliveira Vasconcellos. Empreendedorismo feminino, gênero e liberdade: histórias de mulheres empreendedoras na cidade de Foz do Iguaçu/PR. 2018. 124f. Dissertação (Mestrado em Sociedade, Cultura e Fronteiras) - Universidade Estadual do Oeste do Paraná, Foz do Iguaçu, 2018.

DOLABELA, Fernando. Oficina do Empreendedor. 1 Ed. São Paulo: Cultura Editores Associados, 1999.

DORNELAS, José Carlos Assis. Empreendedorismo: transformando ideias em negócios. Rio de Janeiro: Campus, 2001.

FILION, Louis J. "Empreendedorismo: empreendedores e proprietários-gerentes de pequenos negócios". Revista de Administração - USP, V. 34/2, p. 5-28, 1999.

GIL, A. C. Como elaborar projetos de pesquisa. $4^{a}$ ed. São Paulo: Atlas, 2002.

GOMES, A. F.; SANTANA, W. G. P. \& ARAÚJO, U. P. "Empreendedorismo Feminino: O Estado-daarte". In: Anais do Encontro da ANPAD. São Paulo, 2009.

GOMES, Almiralva Ferraz et al . Empreendedorismo Feminino como Sujeito de Pesquisa. Revista Brasileira de Gestão de Negócios. V. 16, n. 51, p. 319-342, São Paulo, 2014.

GRANT THORNTON. Mulheres e o mercado de trabalho. 14 nov 2019. Disponível em:

https://www.grantthornton.com.br/sala-de-imprensa/14.11-mulheres-e-o-mercado-de-trabalho/. Acesso em: 28 dez 2020.

HISRICH, R. D., \& PETER, M. P. Empreendedorismo. Porto Alegre: Bookman, 2004. 
IBGE EDUCA. Conheça o Brasil - População: quantidade de homens e mulheres. Disponível em: https://educa.ibge.gov.br/jovens/conheca-o-brasil/populacao/18320-quantidade-de-homens-e-mulheres.html. Acesso em: 03 jan 2021.

JONATHAN, Eva G.. Mulheres empreendedoras: o desafio da escolha do empreendedorismo e o exercício do poder. Psicol. clin. V. 23, n. 1, p. 65-85, Rio de Janeiro, 2011.

LANDSTROM, H.; BENNER, M. Entrepreneurship research: A history of scholarly migration. Great Britain: Edward Elgar Publishing, 2010.

LANDSTROM, H.; HARIRCHI, G.; ASTRÖM, F. Entrepreneurship: Exploring the Knowledge base. Research Policy, v. 41, n. 7. p. 1154-1181, set. 2012.

LEITE, Roberto Cintra. De executivo a empresário: como realizar o seu ideal de segurança independência. Rio de Janeiro: Editora Campus, 1998.

LOPES, C. M. S. Direito do trabalho da mulher: da proteção à promoção. Cadernos Pagu (26), janeiro-junho de 2006. Disponível em: http://www.scielo.br/pdf/cpa/n26/30398.pdf. Acesso em: 07 jan 2021.

MACHADO, F. B. “Dilemas de Mulheres Empreendedoras em Empresas Inovadoras Nascentes”. In: Anais do Encontro da ANPAD. 36, Rio de Janeiro, 2012.

MCCLELLAND. David. The Achieving Socity. New York: D. Van Nostrand, 1961.

MIRANDA, C. M. S. Empreendedorismo feminino na Universidade Regional de Blumenau. 2007. 138f. Dissertação (Mestrado em Administração) - Universidade Regional de Blumenau, Blumenau, 2007.

NOVAES, Irlane Regina Moraes. Ana Jansen: emprendedorismo feminino no século XIX. Tese (Doutorado em Administração) - FGV - Fundação Getúlio Vargas, Rio de Janeiro, 2012.

RAPOSO, Kariny C. de Souza; ASTONI, Sílvia A. Ferreira. A mulher em dois tempos: a construção do discurso feminino nas revistas dos anos 50 e na atualidade. Revista do Centro Universitário São Camilo, ES, v. 8, n. 2, p. 36-37, 2007.

SCHUMPETER, J. A. A teoria do desenvolvimento econômico., Nova Cultura. São Paulo, 1988.

SEBRAE, Os desafios da mulher empreendedora, 2016. Disponível em: https://www.sebrae.com.br/sites/PortalSebrae/artigos/os-desafios-da-mulherempreendedora,e74ab85844cb5510VgnVCM1000004c00210aRCRD. Acesso em 15 jan.2021.

SEBRAE. Mulheres e negócios: a força do empreendedorismo feminino. 2020. Disponível em: https://www.sebrae.com.br/sites/PortalSebrae/sebraeaz/mulheres-e-negocios-a-forca-do-empreendedorismofeminino,56ff2a53c6d80710VgnVCM1000004c00210aRCRD. Acesso em 20 jan 2021.

SEBRAE-SC. Empreendedorismo - Mas afinal, o que é empreendedorismo?. SC, nov. 2019. Disponível em: https://atendimento.sebrae-sc.com.br/blog/o-que-e-empreendedorismo/. Acesso em: 5 jan 2021.

SOUZA, Cristiane Gomes de. A mulher de negócios no discurso do trabalho feminino. Rev. Katálysis, v. 23, n. 3, pág. 700-706, Florianópolis, 2020.

\section{APÊNDICE}

Questionário aplicado ao público-alvo delimitado nos procedimentos metodológicos Questionário - Empreendedorismo Feminino no município de São José do Belmonte

1. Qual o nome do seu empreendimento?

2. Qual segmento? 
3. Atualmente, o seu empreendimento é sua principal atividade como fonte de renda ou uma atividade extra?

[ ] Atividade principal

[ ] Atividade extra

4. Qual sua faixa etária?

[ ] Até 18 anos incompletos

[ ] 18 anos completos a 25 anos incompletos

[ ] 25 anos completos a 35 anos incompletos

[ ] 35 anos completos a 45 anos incompletos

[ ] Mais de 45 anos completos

5. Qual seu nível de escolaridade?

[ ] Fundamental completo ou incompleto

[ ] Médio completo ou incompleto

[ ] Superior completo ou incompleto

[ ] Pós-graduação

6. Se a resposta anterior for (SUPERIOR ou PÓS-GRADUAÇÃO) qual seu curso? Existe alguma relação com seu negócio?

7. Qual sua renda mensal?

[ ] Até 1 salário mínimo

[ ] 2 a 3 salários mínimos

[ ] 3 a 4 salários mínimos

[ ] Mais de 4 salários mínimos

8. Quão satisfeita você se sente em relação a sua renda?

[ ] Insatisfeita

[ ] Pouco satisfeita

[ ] Satisfeita

[ ] Muito satisfeita

9. Qual seu estado civil?

[ ] Solteira

[ ] Casada

[ ] Divorciada

[ ] Viúva

10. Você tem filhos?

[ ] $\mathrm{Sim}$

[ ] Não

11. Se a resposta anterior for (SIM) qual a sua relação com o trabalho e a maternidade?

12. Quais foram os FATORES iniciais que te fizeram optar pelo empreendedorismo?

[ ] Interesse ou paixão pelo empreendedorismo

[ ] Busca pela independência financeira

[ ] Visão de oportunidade de mercado

[ ] Liderança

[ ] Continuidade de um negócio de família

[ ] Desemprego

13. Explique sua resposta anterior, caso deseje pode citar mais fatores além do mencionado.

14. Como você começou? Desde quando surgiu o interesse em abrir seu próprio negócio?

15. O que você desejava conquistar quando optou por empreender? Você mantém a mesma visão atualmente?

16. Quais os principais desafios e dificuldades você, como MULHER, enfrentou e enfrenta para empreender?

17. Como você avalia o crescimento do empreendedorismo feminino no mercado e qual a importância disso?

18. Descreva algumas estratégias que você utiliza para lidar com a multiplicidade do papel feminino na sociedade e a gestão do seu negócio.

19. Você acha que o exercício de poder da mulher também provoca mudanças significativas nos aspectos sociais e culturais? Explique. 